Aletria, Belo Horizonte, v. 29, n. 1, p. 141-164, 2019

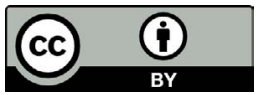

\title{
Ruggero Jacobbi, intérprete de Carlo Goldoni: a comedia italiana e o teatro brasileiro moderno
}

\section{Ruggero Jacobbi, interpreter of Carlo Goldoni: Italian comedy and Brazilian modern theater}

\author{
André Luis Bertelli Duarte \\ Universidade Federal de Uberlândia (UFU), Uberlândia, Minas Gerais / Brasil \\ andrebduarte@gmail.com
}

Resumo: $\mathrm{O}$ artigo investiga a encenação e recepção crítica de três comédias de Carlo Goldoni, realizadas por Ruggero Jacobbi no Brasil, entre 1949 e 1955. O objetivo é evidenciar como a leitura de textos da comédia italiana subsidiou experimentações estéticas e debates sobre o teatro e a sociedade brasileira no período.

Palavras-chave: Carlo Goldoni; Ruggero Jacobbi; comedia italiana; teatro brasileiro moderno.

Abstract: The article investigates the staging and critical reception of three comedies by Carlo Goldoni conducted by Ruggero Jacobbi in Brazil between 1949 and 1955. The aim is to show how the reading of Italian comedy texts subsidized aesthetic experiments and debates about theater and society in the period.

Keywords: Carlo Goldoni; Ruggero Jacobbi; Italian comedy; modern Brazilian theater.

Em um artigo publicado no ano de 1965, intitulado Por que Goldoni, hoje?, o crítico teatral francês Bernard Dort se mostrava surpreso com a quantidade de encenações da obra do dramaturgo veneziano que podiam ser vistas não apenas na Itália, mas também na França, Alemanha e nos Estados Unidos desde o início do século XX. A resposta encontrada por ele para a questão sublinhada no título era de 
que duas tradições diferentes, entre as mais férteis para a cena do teatro moderno, reclamavam a obra de Goldoni: de um lado, a do naturalismo, que retomava formas do realismo do século XIX; de outro, a tradição do teatro popular de improvisação, da commedia dell'arte, ou pelo menos uma concepção moderna e estilizada. Para comprovar a sua tese, Dort rememorava a encenação seminal de La Locandiera, de Goldoni, por Stanislávski no Teatro de Arte de Moscou, de 1898, como expoente primeiro dos esforços em resgatar a dramaturgia do autor veneziano a partir de seu realismo. Por outro lado, também relembrava a encenação de Il servitore di due padroni, de Goldoni, por Max Reinhardt, em 1932, como representante de outra maneira de enfrentar o dramaturgo, a saber, a partir do privilégio das fontes populares de sua obra encontradas no exercício do autor com as formas da commedia dell'arte. ${ }^{1}$

Estas duas tradições que reclamam a obra de Goldoni e que foram resgatadas na cena do teatro moderno do século XX evidenciam, em primeira análise, uma contradição: como um autor pode ser lido, ao mesmo tempo, como expoente de um teatro de cunho realista/naturalista e também como fonte para o exercício de um teatro fantástico fundado nas formas improvisadas da commedia dell'arte?

Este fato decorre do próprio caráter ambíguo da obra do dramaturgo. Goldoni, na primeira metade do século XVIII, começou sua carreira de comediógrafo escrevendo roteiros (canovacci) destinados à improvisação dos atores italianos especializados nos tipos fixos das máscaras cômicas da commedia dell'arte que, naquele momento, ainda gozavam de grande prestígio junto ao público italiano e europeu. Ao longo do desenvolvimento de suas pesquisas dramatúrgicas, entretanto, Goldoni colocou em prática um projeto de reforma da comédia italiana que partia do princípio da valorização da comédia enquanto poesia, ou seja, gênero literário que não poderia prescindir do poeta. Deste modo, a reforma teatral capitaneada por Goldoni procurou "abolir" os espaços destinados à improvisação dos atores a partir da escritura integral do texto teatral, dotando-o de complexidade psicológica, uma vez que os personagens seriam criados por meio da observação da realidade social em que viviam. Este processo de transformação encontrou suas formas tanto na escrita dos textos dramáticos quanto nas suas encenações realizadas ao longo do tempo. Com efeito, de Il Servitore de due padroni

\footnotetext{
${ }^{1}$ DORT. Por que Goldoni, hoje?, p. 130.
} 
(1746) a La Locandiera (1753) podemos acompanhar as mudanças empreendidas pelo comediógrafo em seus esforços de criação de uma comédia nova, onde os caracteres foram contornados com novos matizes, mais condizentes com a civilidade burguesa que se fazia presente nas suas produções.

No Brasil, a obra teatral de Goldoni passou a ser revisitada mais sistematicamente por artistas e companhias nacionais a partir da década de 1940, no contexto das discussões sobre a modernização do teatro brasileiro. Encontramos o autor, por exemplo, tanto no repertório da Companhia Procópio Ferreira, no ano de 1942, em O Inimigo das Mulheres - naquela que marcaria a estreia de Bibi Ferreira nos palcos -, quanto no do grupo Os Comediantes, que, na paradigmática temporada de 1943 - onde foi encenada Vestido de Noiva, de Nelson Rodrigues, por Ziembinski, marco do teatro moderno no Brasil-, encenou OLeque, com direção de Adacto Filho. Nos dois casos citados, Goldoni era interpretado em sua chave moderna/realista, como um dos maiores expoentes de um teatro de comédia produzido por um dramaturgo dotado de gênio, condizente, portanto, com os anseios artísticos e culturais dos defensores da modernização teatral no Brasil. ${ }^{2}$

Uma mudança sensível na maneira de ler e encenar Goldoni ocorreria no final da mesma década de 1940 , quando a cena teatral brasileira passou a receber a influência de artistas vindos da Europa, notadamente da Itália. Um deles, em especial, empreendeu esforços significativos para oferecer outras chaves interpretativas sobre a obra do comediógrafo para o público brasileiro: Ruggero Jacobbi. Entre 1949 e 1955, Jacobbi encenou, por diferentes companhias no Rio de Janeiro e São Paulo, três espetáculos de Carlo Goldoni, além de escrever textos informativos e proferir palestras sobre o dramaturgo em diferentes espaços. Estes esforços mudaram substancialmente a recepção da obra de Goldoni no Brasil, incorporando aquilo que havia de mais atual nas pesquisas e experimentações realizadas na Europa sem, contudo, desprezar as possíveis interfaces com a cultura brasileira do período. Este artigo é, portanto, uma investigação de como seu deu este processo.

\footnotetext{
${ }^{2}$ BERTELLI DUARTE. Apropriações históricas e releituras estéticas da comedia de Carlo Goldoni pela modernização artística no Brasil do século XX.
} 


\section{Arlequim, servidor de dois amos pelo "Teatro dos 12"}

Ruggero Jacobbi chegou ao Brasil em 1946 como diretor da turnê da companhia de Diana Torrieri que excursionava pela América do Sul. O que era para ser uma temporada breve se tornou uma estadia de 15 anos, marcados por uma intensa atividade como diretor, ensaísta, professor e pensador das artes no país. ${ }^{3}$ Nos seus primeiros anos de atividades no teatro brasileiro, Jacobbi colaborou com figuras como Procópio Ferreira, Alda Garrido e Rodolfo Meyer, além da companhia dirigida pelos atores Sandro Polônio e Maria Della Costa. No início de 1949, foi convidado por jovens amadores egressos do Teatro do Estudante, de Paschoal Carlos Magno, para dirigir o recém fundado "Teatro dos Doze", que contava com figuras como Sérgio Cardoso, Sérgio Britto, Zilah Maria, Elysio de Albuquerque, Luís Linhares, Jaime Barcelos, Beyla Genauer, entre outros.

No seu espetáculo de estreia, teve a oportunidade de encenar um de seus dramaturgos favoritos: Carlo Goldoni. Preocupado em dimensionar o teatro de Goldoni na historicidade de sua evolução, selecionou o texto Il Servitore di due Padroni que, na tradução brasileira realizada por sua esposa Carla Civelli, recebeu o nome de Arlequim, servidor de dois amos. O texto foi "escrito" por Goldoni durante sua estadia em Pisa no ano de 1745 para a companhia de Antonio Sacchi, que o representou pela primeira vez no teatro San Samuele de Veneza em 1746. Inicialmente, Goldoni escreveu um canovaccio com grandes espaços para a improvisação dos comediantes; alguns anos depois, em 1753 , escreveu o texto completo para inclúi-lo no terceiro volume da edição Paperini de suas obras.

Desse modo, percebe-se claramente que o Servidor de dois amos pertence no conjunto da dramaturgia goldoniana, muito mais ao universo das máscaras e da tradição da commedia dell'arte do que obras posteriores, onde a reforma da comedia empreendida por ele se evidencia, como Teatro Comico, Il Ventaglio, ou La Locandiera. Com o Arlequim, portanto, Ruggero Jacobbi via uma oportunidade para situar os atores e os espectadores no universo da commedia dell'arte a partir de uma matriz interpretativa italiana delimitada historicamente, uma vez que reconhecia que os brasileiros conheciam os tipos e personagens

\footnotetext{
${ }^{3}$ Para uma biografia artística e intelectual de Ruggero Jacobbi, e um estudo das atividades realizadas nos anos em que esteve no Brasil, consultar: RAULINO. Ruggero Jacobbi: presença italiana no teatro brasileiro.
} 
da commedia dell'arte a partir da leitura que o romantismo do século XIX, principalmente na França, fazia deste universo, que se distanciava substancialmente das formas italianas dos séculos XVI e XVII que estavam sendo resgatadas naquele momento não somente na Itália conforme os esforços de Giorgio Strehler, Anton Giulio Bragaglia, entre outros -, mas em toda a Europa - Max Reinhardt, Meyerhold, etc.

$\mathrm{O}$ diretor fez um longo e exaustivo trabalho teórico com os atores para apresentar-lhes a sua leitura da commedia dell'arte que depois se transformou em uma série de palestras e programas de rádio intitulada "Introdução aos milagres do povo", nascida, nas palavras do próprio diretor, do desejo manifestado por muitos "em conhecer mais sobre Goldoni e sobre a commedia dell'arte". ${ }^{4}$ Neste estudo, Jacobbi destacava o desenvolvimento espetacular do teatro de improvisação desde suas origens no teatro grego e, principalmente, romano (a sátia lanx, o mimmo, a atellana) até o seu período mais fecundo, no século XVI, quando os atores dell'arte gozavam de grande prestígio nas principais cortes europeias, para apresentar, por fim, o lugar de Carlo Goldoni no estabelecimento de novas formas para este tipo de teatro. O comediógrafo, neste sentido, teria dotado as máscaras de maior complexidade psicológica e social e, aos poucos, reduzindo os espaços para a improvisação dos atores a partir da fixação de um texto teatral escrito.

Falando especificamente sobre Arlequim, servidor de dois amos, ele dizia claramente que o seu objetivo com a encenação do texto era travar uma experiência estética, "por espírito e técnica", com as formas da commedia dell'arte e não com a dramaturgia goldoniana propriamente dita. Goldoni, no período, era associado pelos brasileiros exclusivamente à reforma teatral que teria sepultado as formas do teatro improvisado. ${ }^{5}$ Parecia estranho, deste ponto de vista, que o diretor italiano quisesse dar um exemplo da commedia dell'arte justamente com um texto de Goldoni. Com isso, Ruggero Jacobbi abria novas possibilidades estéticas para as interpretações do teatro goldoniano no teatro brasileiro.

A análise do ensaio de Ruggero Jacobbi revela que o seu enfrentamento com a commedia dell'arte por meio do espetáculo

\footnotetext{
${ }^{4}$ MAGNO. Estréia, hoje, no Ginástico, “Arlequim, servidor de dois amos”, de Goldoni, p. 13.

${ }^{5}$ BERTELLI DUARTE. Apropriações históricas e releituras estéticas da comedia de Carlo Goldoni pela modernização artística no Brasil do século XX.
} 
Arlequim, servidor de dois amos obedecia a dois princípios centrais: por um lado, o diretor queria resgatar as possibilidades interpretativas do teatro improvisado, cujas formas eram interpretadas por ele como um "espírito" que perpassa a comicidade popular ao longo do tempo, desde os tempos da Roma Antiga; por outro, havia o interesse de explorar as potencialidades dos tipos fixos, das máscaras, e sua capacidade histórica de promover uma "perpétua oscilação entre a tendência a fixar tipos universais e o gosto da atualidade histórica e social". 6

$\mathrm{Na}$ entrevista que o diretor concedeu a Paschoal Carlos Magno no dia da estreia do espetáculo, ele reforçou esta ideia de que o "espírito" da commedia dell'arte deveria ser buscado na representação dos atores, realística e fantástica ao mesmo tempo, antiacadêmica, cheia de surpresas e de uma infinita naturalidade: "os milagres de técnica e de intuição que hoje observamos em grandes comediantes, até na revista e no cinema, e mesmo aqui no Brasil, num Oscarito e numa Alda Garrido, descendem todos, em linha direta, da commedia dell 'arte". ${ }^{7}$ Em outras entrevistas concedidas a periódicos cariocas, quando foi questionado se o seu objetivo era dar um exemplo do teatro italiano, Ruggero Jacobbi enfatizou que o seu Arlequim era brasileiro, e que ele seria louco se, para um público brasileiro, tentasse produzir um espetáculo italiano, francês ou alemão. Neste sentido, o diretor tentou incentivar os atores, especialmente o protagonista Sérgio Cardoso, a buscarem na composição dos personagens referências nacionais, de forma a facilitar a comunicação e o entendimento do público:

No meu Arlequim, a maior dificuldade foi convencer o esplêndido Sérgio Cardoso a deixar um pouco de lado as suas preocupações de elegância e a não fechar $a$ porta aos espiritozinhos nacionais do moleque negro, do Saci-Pererê, do dançarino grotesco índio, do carioca carnavalesco. O sucesso foi também estupor. ${ }^{8}$

Como observador "externo" do processo de modernização do teatro brasileiro, Jacobbi via nos atores uma preocupação excessiva com

\footnotetext{
${ }^{6}$ JACOBBI. Goldoni e a "commedia dell'arte", p. 74.

${ }^{7}$ MAGNO. Estréia, hoje, no Ginástico, “Arlequim, servidor de dois amos”, de Goldoni, p. 13, grifo nosso.

${ }^{8}$ JACOBBI. Meditazioni su um mito e su una biografia, p. 63, grifos nossos.
} 
o estilo, ou com a "elegância", como ele mesmo denomina. Isto resultava em uma atuação correta, mas forçosamente construída. Ele sabia que o sucesso do seu espetáculo dependia de que os atores, principalmente o Arlequim Sérgio Cardoso, abrissem mão destas preocupações de estilo e buscassem incorporar o "espírito" do teatro improvisado, de modo a construir um repertório gestual mais condizente com a proposta de enfrentamento com a estética da commedia dell'arte. O diretor procurou identificar, portanto, em alguns "tipos" nacionais elementos que fizessem referência à comicidade popular e incentivou os atores a exercitarem gestos e formas que permitiriam o "abrasileiramento" da representação. ${ }^{9}$ Desse modo, a commedia dell'arte era vista por Jacobbi como uma oportunidade de aprofundamento técnico do trabalho dos atores necessário para a plena conquista da modernidade teatral no Brasil. Por outro lado, o diretor também enxergava neste tipo de teatro uma possibilidade para trabalhar esteticamente os tipos e as máscaras, universais, em suas possíveis interfaces com a atualidade histórica e social.

$\mathrm{O}$ enredo de Arlequim, servidor de dois amos, de Goldoni, enfatiza as peripécias de um criado (Arlequim) que se desdobra para servir simultaneamente a dois senhores. No entanto, Arlequim é atrapalhado e distraído, o que o conduz a situações embaraçosas e cômicas. Ele não é o personagem central da peça, mas as ações e embaraços ganham relevo por meio de suas trapalhadas, o desenvolvimento da trama adquire contornos irônicos a partir de seus comentários. No desenvolvimento da dramaturgia goldoniana, os servidores se transformarão, paulatinamente, em possibilidades de relativização e crítica da razão e da moral burguesa do século XVIII pensadas em termos absolutos. ${ }^{10}$

Assim sendo, o servidor de dois amos do texto de Goldoni não é propriamente o modelo de trabalhador virtuoso, esforçado, obediente e prudente, ao contrário, engana os patrões, mente, come em serviço, etc.; ou seja, seu personagem é, em determinado nível, um crítico da moral burguesa que o próprio dramaturgo exaltava, sobretudo, nos textos dos primeiros anos de sua reforma teatral.

A maneira encontrada por Ruggero Jacobbi para relacionar esta dimensão crítica do servidor de dois amos com a realidade do

\footnotetext{
${ }^{9}$ MAGNO. Estréia, hoje, no Ginástico, “Arlequim, servidor de dois amos”, de Goldoni, p. 13.

${ }^{10}$ FIDO. Guida a Goldoni: teatro e società nel Settecento. p. 103.
} 
espectador brasileiro é por meio da associação do Arlequim com a figura do "malandro" carioca. Em mais de uma matéria de jornal publicada em $\backslash$ periódicos na ocasião da estreia do espetáculo dos "12", os atores relacionam os dois personagens. No Jornal de Notícias, por exemplo, a reportagem que tratava do espetáculo intitulava-se mesmo "Onde o Arlequim se confunde com o malandro brasileiro". No texto da reportagem, um dos atores observou que "Arlequim tem muito de parecido com o malandro brasileiro"; e o próprio Ruggero Jacobbi afirmou que "todos os malandros são irmãos", e que este Arlequim de Bérgamo tocaria o público da mesma forma como estava comovendo as plateias em toda a Europa. ${ }^{11}$

A associação entre a personagem Arlequim e o malandro carioca, em fins dos anos 1940, traz em si possibilidades interpretativas interessantes, uma vez que o tema da malandragem associada à rejeição do trabalho foi duramente combatido durante o governo de Getúlio Vargas, sobretudo durante os anos de vigência do Estado Novo. Para construir uma imagem de nação "nova" e "moderna" e exercer o controle sobre o trabalho e o trabalhador, o governo Vargas e seus departamentos - principalmente o de Imprensa e Propaganda (DIP) - investiram na exaltação do trabalho e do trabalhador como valores centrais de civilidade e nacionalismo. Dessa forma, o regime procurava legitimar um discurso que demonstrasse para os trabalhadores a importância de valores como o esforço, a obediência e a prudência na construção da "nova" república inaugurada com a Revolução de 1930. Neste sentido, a figura do malandro associada não somente com a recusa do trabalho, mas com o jogo, o morro e o samba, desde o final do século XIX, deveria ser combatida pela ideologia estadonovista.

Quando o espetáculo do Teatro dos Doze estreou nos palcos cariocas, Getúlio Vargas e o Estado Novo haviam, aparentemente, ficado para trás e o país convivia com a perspectiva da democracia. Entretanto, os valores nacionais forjados alguns anos antes para a construção do "futuro da nação" ainda encontravam-se frescos, especialmente no que se refere a valores como a família e o trabalho (a própria eleição de Vargas no ano seguinte comprovam isto), o que nos permite precisar que a associação entre o malandro carioca e o Arlequim realizada por Ruggero Jacobbi se encontrava atual como forma de realização crítica.

${ }^{11}$ FURQUIM. Onde o Arlequim se confunde com o malandro brasileiro. p. 3. 
No espetáculo, Ruggero Jacobbi procurou trabalhar esteticamente esta dimensão do personagem por meio do jogo cênico. A maneira como Arlequim se move em cena - incorporando referências, segundo vimos, do moleque negro, do saci-pererê, do dançarino índio - possibilita uma rejeição gestual da dinâmica do mundo do trabalho moderno, repleto de repetições, e chama a atenção para uma maneira outra de estar no mundo, inspirada em valores tradicionais associados à improvisação.

Estas foram, portanto, as soluções encontradas por Ruggero Jacobbi para aproximar as suas intenções em trabalhar com as formas da commedia dell'arte, através de Goldoni, e o universo teatral e social brasileiro daquele período. A sua pouca familiaridade com a cultura brasileira, a dificuldade na tradução do texto e, sobretudo, o respeito à convenção de que o espetáculo devia ser a interpretação, mais fiel possível, do texto teatral o impediram de alçar voos mais altos na relação entre a comédia italiana e a cultura brasileira. No entanto, seu esforço em criar um espaço comum de discussão e circulação entre o teatro italiano e o teatro brasileiro, fundado na devida mediação histórica, deve ser considerado como uma iniciativa importante nos caminhos da renovação do teatro brasileiro por revelar perspectivas diferentes no enfrentamento com o repertório, a encenação e a formação do ator.

\section{O Mentiroso: Goldoni e Ruggero Jacobbi no TBC}

O sucesso de público e crítica de Arlequim, servidor de dois amos levou Jacobbi a ser contratado no mesmo ano como diretor permanente do Teatro Brasileiro de Comédia, o TBC, fundado por Franco Zampari, em São Paulo. Logo em seus primeiros espetáculos para a casa, o diretor voltou-se mais uma vez para a dramaturgia goldoniana, selecionando um texto que pertence ao período de transição entre a commedia dell'arte e a comédia burguesa, ou seja, O Mentiroso (1751) ainda possuía elementos das máscaras e das características do teatro de improvisação, mas o dramaturgo havia escrito todo o texto e promovido um aprofundamento psicológico do seu protagonista, Lélio dos Bisonhos.

O texto que Jacobbi escreveu para o programa do espetáculo, cuja estreia se deu no palco do TBC em 23 de novembro de 1949, revela as intenções e as perspectivas que ele possuía não somente em sua leitura da obra do dramaturgo, mas também sobre o teatro brasileiro daquele período. $\mathrm{O}$ diretor apontava a relação de hereditariedade que via entre 
"as invencionices e trapalhadas de Arlequim e a imaginação espetacular de Lélio". Isto porque o desenvolvimento dos tipos goldonianos, da "máscara" ao "caráter", teria sido muito significativo e gradual. Este desenvolvimento gradual da máscara ao caráter na dramaturgia goldoniana seria devido ao fato de que Goldoni não era um literato, mas um homem de teatro, por isso, sabia muito bem que a história não se processa por golpes de cena: "estes acontecem apenas no palco - e nesse caso também temos uma prova da natural diferença entre a vida e a literatura, estabelecida pelo processo de síntese e estilização que não é um segredo dos escritores fantásticos e sim dos grandes realistas." 12

Aprofundando um pouco mais a relação entre o caráter complexo de Lélio e a "série de caracteres simples" das máscaras, Ruggero Jacobbi observava a existência de uma linha divisória impalpável entre as trapalhadas de Arlequim e as fanfarronadas de Lélio:

Aquele [Arlequim], mais inocente e simplório, acaba nos fornecendo a imagem de um mundo inteiramente cínico; este [Lélio], bem cínico e às vezes perfeitamente criminal, revela, contudo, a existência de um problema ético. São dois séculos que se defrontam: o Seiscentos libertino e o Setecentos burguês. A evolução da consciência moral se faz sentir, e com uma força cujas conseqüências escapam ao próprio Goldoni: ouve-se ao longe o roncar, ainda incerto, do trovão revolucionário. ${ }^{13}$

Jacobbi retoma, com isto, alguns argumentos que havia explicitado no ensaio que produziu para a encenação de Arlequim, servidor de dois amos naquele mesmo ano, ou seja, reitera o lugar de Goldoni como um ponto de referência para se pensar, pelo viés artístico, as mudanças fundamentais ocorridas no século XVIII decorrentes da ascensão do projeto político, cultural e moral burguês. No entanto, ele nunca perde de vista que isso não significa que Goldoni deva ser entendido como porta-voz de uma ruptura completa com o universo artístico que o precede, mas, ao contrário, que Arlequim, servidor de dois amos poderia ser vista como o "relato taquigráfico de uma comédia improvisada, coordenado por uma mente lógica e pela unidade do estilo", OMentiroso deveria ser vista como

${ }^{12}$ JACOBBI. Reflexões sobre "O mentiroso", p. 18.

${ }^{13}$ JACOBBI. Reflexões sobre "O mentiroso", p. 19-23. 
"uma peça inteiramente pensada e escrita, mas que conserva o perfume da improvisação como uma saudade capaz de se articular em um ritmo". Isto é, mesmo que o desenvolvimento do caráter de Lélio revele o florescimento de um problema ético burguês, suas ações, seus ritmos, continuam sendo inspirados pelos tipos do teatro de improvisação pré-burguês. ${ }^{14}$

Assim como em Arlequim, servidor de dois amos, a sua preocupação central era pensar como um texto produzido há exatos duzentos anos, ou seja, em um período histórico completamente diferente daquele da cena teatral, poderia ser representado para o público moderno. Sobre isso, chamava a atenção para o problema "da colocação das personagens, de fala e espírito sempre modernos, dentro de uma moldura de 'estilização-histórica' - dentro de uma história-atmosfera, de uma história-poesia, capaz de sugerir o sentimento do antigo e, mais ainda, do eterno". Esta perspectiva de "estilização histórica" só seria possível mediante "uma livre e sistemática falta de respeito à históriadocumento". ${ }^{15}$ Abrindo mão de uma interpretação arqueológica do texto e da obra de Goldoni, Ruggero Jacobbi pôde justificar algumas "licenciosidades" e outras "arbitrariedades" que realizou na montagem do texto. O diretor optou por encerrar a peça com o lazzo (sugerido por Adolfo Celi e já experimentado por outros intérpretes) da última mentira de Lélio diante do pai, Pantaleão. Esta foi apenas a última das liberdades que, segundo ele próprio, já havia tomado:

Transferência das piadas mais regionais para um registro popular moderno; cortes e, alguns deles, violentos; reconstituição da figura tradicional do Doutor, com seu repertório de frases latinas etc. Utilizei também uma cena de Os Três Malandros, da coleção francesa de Gherardi, bíblia da comédia improvisada: e umas frases e piadas felizes de uma velha tradução que Procópio (Ferreira), certa vez, me mostrou. Transformei Brighela num Polichinelo, máscara muito mais viva hoje em dia e que não corre o perigo, típico do Brighela, de se tornar uma

${ }^{14}$ Para um aprofundamento sobre a interpretação histórica e estética de Ruggero Jacobbi de O Mentiroso, consultar: DUARTE. O caráter na comedia de Carlo Goldoni: apropriações históricas de "O Mentiroso" (Il Bugiardo) entre a Itália e o Brasil, p. 52-76. ${ }^{15}$ JACOBBI. Reflexões sobre "O mentiroso", p. 23. 
espécie de doublé do Arlequim. Perdoai-me por isso, pois Goldoni já me perdoou. ${ }^{16}$

Em O Mentiroso, Ruggero Jacobbi responsabilizou-se pela tradução e pela adaptação do texto teatral. Fica evidente em sua fala que o seu grande esforço se concentrou na atualização do texto para o público contemporâneo, atualização esta que procurou ressaltar o que o poderia haver de mais "popular", uma vez que o diretor utilizou não somente trechos já consagrados pela tradição cômica do teatro improvisado (Gherardi), como também amplos trechos da tradução de Gastão Pereira da Silva que possuía uma atualidade latente no uso de expressões cômicas próprias do Brasil daqueles anos.

No texto que escreveu para o programa da peça, Ruggero Jacobbi recordou que o seu objetivo com o Arlequim era oferecer ao público um exemplo não de Goldoni, mas da commedia dell'arte. Em seguida, havia afirmado que se quisesse dar um exemplo da arte goldoniana teria escolhido O Leque, O Mentiroso ou A Família do Antiquário. Entretanto, observava que agora que estava ensaiando $O$ Mentiroso, estava lhe saindo das mãos uma commedia dell'arte. O diretor, neste sentido, arrematou: "Mas a culpa não é minha: é de Goldoni”. Será? A partir da exposição dos elementos e reflexões que permearam a montagem do espetáculo fica evidente que o diretor faz um esforço significativo para aproximar o texto de Goldoni da commedia dell'arte. Conforme observou Betti Rabetti: "não seria servilismo demais ao autor clássico veneziano, por parte de quem acabou de falar na 'história-poesia' que descarta a 'história-documento'?"17

De fato, Ruggero Jacobbi assume conscientemente as liberdades que tomou para transformar $O$ Mentiroso em um espetáculo com o "espírito" do teatro de improvisação. Ele tenta justificar as suas opções enfatizando que o texto pertencia estritamente ao século XVIII: era uma peça burguesa, um testemunho do momento afirmativo da burguesia italiana, ou seja, não era mais representante do universo da commedia dell'arte que significava, antes, "século XVII, barroco, espanholismo". ${ }^{18}$ Neste sentido, abordar o texto a partir de uma atitude em busca da "história-documento" significaria, para ele, colocar em relevo, de forma positiva, os valores-testemunho do momento afirmativo da burguesia

\footnotetext{
${ }^{16}$ JACOBBI. Reflexões sobre "O mentiroso", p. 37-39.

${ }^{17}$ GIANNELLA. Contribuição para o estudo do "Moderno Teatro Brasileiro", p. 266.

${ }^{18}$ JACOBBI. Reflexões sobre "O mentiroso", p. 37-39.
} 
italiana. Trazendo para o seu tempo presente, significaria positivar estes mesmos valores burgueses, mais presentes do que nunca, que as formas do teatro popular, ao contrário, permitiam criticar. Ao encenar as comédias de Goldoni a partir de uma "justa perspectiva histórica", ${ }^{19}$ Ruggero Jacobbi sabia que teria que se defrontar com o tema da moral e da civilidade burguesa que a obra do dramaturgo reclamava; como homem de esquerda do século XX, o diretor procurou incorporar nesta discussão novas perspectivas que o permitissem abordar o problema sob uma ótica diferente.

Em seu projeto reformador, Goldoni defendia que a comédia fora levantada para castigar os vícios e pôr em ridículo os maus costumes da sociedade. Seus personagens reconheciam que "quando o protagonista da comédia tem maus costumes, ou se redime de acordo com os bons preceitos, ou a comédia redunda numa imoralidade". ${ }^{20}$ Sendo assim, o protagonista de $O$ Mentiroso, Lélio dos Bisonhos, é um personagem que possui maus costumes, a saber, é mentiroso compulsivo e mente para tirar proveito das situações, sejam elas amorosas ou financeiras. Na peça, seu caráter é confrontado pelo caráter de seu pai, Pantaleão dos Bisonhos, mercador íntegro e honesto, cuja reputação acaba sendo questionada pelo mau-caratismo do filho. Nestes primeiros anos de efetivação de seu projeto reformador, Goldoni investiu toda a carga moral na figura dos mercadores, ou seja, para que a comédia cumprisse o seu papel de castigar os vícios e pôr em ridículo os maus costumes, Lélio devia se redimir de acordo com os bons preceitos, cujo principal expoente era o seu próprio pai. Ao fim da peça, Lélio acaba por se remir perante os demais personagens se justificando que as suas mentiras tinham por objetivo único trazer à tona a verdade. No texto adaptado por Ruggero Jacobbi, esta cena final onde Lélio se redime perante todos se configura da seguinte maneira:

Lélio [em atitude solene]: Muito bem! Agora que estão todos presentes, quero fazer uma declaração! Saibam que eu preguei todas essas mentiras apenas para obrigar a verdade a se revelar!

Todos [curiosos]: Como?

${ }^{19}$ JACOBBI. Reflexões sobre "O mentiroso", p. 37-39.

${ }^{20}$ GOLDONI. O teatro cômico, p. 27-28. 
Lélio: Porque se não fosse eu, este idiota jamais revelaria o seu amor por Dona Rosaura nem esse cretino a D. Beatriz! Sim... eu sabia que o Dr. Balanção tinha desejo de casar Rosaura com o Sr. Florindo; eu sabia que o Sr. Otávio amava a Beatriz. Mas a timidez reprimia a verdade! E como a verdade é inimiga feroz da mentira, foi preciso tocá-la com o florete da minha astuciosa imaginação, para que ele se revoltasse e viesse subjugar a sua maior inimiga: a mentira! (olhares curiosos e aquiescência tácita de todos) Arlequim [a parte]: É um bicho! Tem talento como o diabo! ${ }^{21}$

O que na peça de Goldoni constituía o momento de redenção moral de Lélio é ressignificado por Ruggero Jacobbi como mais uma de suas mentiras, o que revela todo o seu cinismo. $\mathrm{O}$ cinismo do seu caráter é acentuado e reafirmado pelo comentário à parte de seu criado Arlequim, conhecedor das fanfarronadas do seu amo, e que atua no espetáculo, como em vários outros, como o comentarista do enredo em chave irônica e crítica. Antes do espetáculo se encerrar, como que se justificando para a plateia, Lélio declara: "Só há nisto uma verdade absoluta, inviolável: sou livre e livre quero ficar, porque eu só amo a minha liberdade! Adeus, senhores! Vamos Arlequim!... Adeus!". ${ }^{22}$ Ao encerrar o espetáculo desta maneira, Jacobbi acaba por negar, a partir da liberação de Lélio, o princípio moralizador que o texto de Goldoni tinha em alta conta. Deste modo, o Lélio de Jacobbi defendia a liberdade de se opor à civilidade burguesa representada por seu pai, Pantaleão, ou seja, o seu jogo cínico permite escancarar o modo como a correção dos costumes burguesa opera e, em última análise, rejeitá-la a partir da defesa da liberdade de ação moral do protagonista.

O Mentiroso foi, sem dúvida, o grande sucesso da temporada teatral paulistana de 1949/1950, como também um dos mais aclamados espetáculos da história do Teatro Brasileiro de Comédia. O sucesso foi tamanho que o espetáculo voltou ao repertório da casa em 1952, novamente com a direção de Ruggero Jacobbi e com Sérgio Cardoso no papel de protagonista. Não há uma referência ao diretor italiano no teatro brasileiro que não faça menção a $O$ Mentiroso como a sua maior criação cênica no período em que ficou no Brasil. Podendo realizar um espetáculo

${ }^{21}$ GOLDONI. $O$ Mentiroso, p. 80.

${ }^{22}$ GOLDONI. O Mentiroso, p. 80. 
"ao seu gosto" e "à sua maneira", com as condições econômicas e artísticas mais favoráveis possíveis, Ruggero Jacobbi fez mais do que contribuir para o processo de renovação teatral que se encontrava em curso no período: ele apontou caminhos frutíferos para o enfrentamento com a comédia a partir da incorporação das suas formas populares.

\section{Mirandolina pelo Teatro Popular de Arte}

A última encenação goldoniana dirigida por Ruggero Jacobbi no Brasil foi Mirandolina, junto ao Teatro Popular de Arte (TPA), de Sandro Polônio e Maria Della Costa, em 1955. Neste período, o diretor já se encontrava afastado das atividades do Teatro Brasileiro de Comédia após a polêmica envolvendo a sua encenação de $A$ Ronda dos Malandros, em 1950.

O diretor já havia trabalhado com o casal de atores e o Teatro Popular de Arte na ocasião de sua chegada ao país em meados da década de 1940. Em 1948, dirigiu um dos grandes sucessos do grupo, A Estrada de Tabaco, de Erskine Caldwell e Jack Kirkland. No mesmo ano, em nova parceria com o grupo, encenou Tereza Raquim, de Zola. Por tudo isso, além das experiências exitosas do diretor com os textos de Goldoni, os diretores do TPA convidaram-no para dirigir Mirandolina, na capital paulistana.

O desejo de montar Mirandolina já era alimentado por Maria Della Costa desde 1953, ocasião em que ela teve a oportunidade de assistir, na Itália, a realização de Luchino Visconti, com Rina Morelli e Marcelo Mastroianni. Nesta mesma viagem, inclusive, ela e Sandro Polônio fizeram o convite para que Gianni Ratto assumisse o posto de diretor artístico da companhia. No espetáculo goldoniano de 1955, entretanto, o diretor foi Ruggero Jacobbi e Ratto ficou responsável por cenários e figurinos.

Como nas demais montagens do autor veneziano que realizou em solo brasileiro, Jacobbi escreveu um texto para o programa do espetáculo em que expunha sua visão sobre o lugar do texto na dramaturgia de Goldoni, além de apresentar sua visão geral da encenação. Em Bom dia, Mirandolina, o diretor inicia apresentando a Locandiera, "do veneziano Carlo Goldoni, com músicas do veneziano Antonio Vivaldi, dirigida pelo veneziano Ruggero Jacobbi". ${ }^{23}$ Os três venezianos, entretanto, se viam às

${ }^{23}$ JACOBBI. Bom dia, Mirandolina, p. 11. 
voltas com uma toscana, uma vez que Goldoni ambienta o enredo da peça em uma estalagem da Toscana. O diretor questionava-se se o espectador brasileiro perceberia tais distinções regionais, tão fortes em solo italiano:

O fato é que a comédia de Mirandolina é toscana, florentina mesmo, espalhando em volta de si a graça, a malícia e a doçura que reinam nas colinas de Fisole e de San Miniato, sob os ciprestes de San Giminignano, em meio ao mistério das quietas vegetações que despontam por cima dos muros brancos. ${ }^{24}$

A ênfase nesta mudança de ambiente, de acordo com Ruggero Jacobbi, teria o intuito de revelar ao espectador que ele estava, de fato, diante de um "outro" Goldoni, outro e maior, acrescenta:

A diversidade não vem apenas do ambiente, que deixou de ser veneziano; vem da concepção e do estilo, que dobraram a esquina perigosa da commedia dell'arte para inaugurar o realismo moderno, a comédia de costumes, psicológica e social. ${ }^{25}$

Desta maneira, o diretor se mostrava afinado com aquilo que era produzido em solo italiano, principalmente se pensarmos que a encenação de Luchino Visconti inaugurou a chamada "estação do realismo" goldoniano, que propunha interpretações muito fortemente marcadas pela crítica histórica e social. Diferentemente de Visconti, no entanto, Ruggero Jacobbi ainda via no texto algumas possibilidades de referência ao universo da comédia improvisada:

Da commedia dell'arte fica o cheiro, vago, impalpável, pairando no ar, devido a certos fatores externos. Mirandolina é Colombina, Coralina, Esmeraldina, transformadas, superadas, concretizadas. O papel foi escrito para a famosa Coralina, mas nasceu dentro de Goldoni devido à força de uma experiência humana, de uma observação real. [...] A polêmica contra a commedia dell'arte, esta sim, continua viva, apresentando Goldoni aquelas duas cômicas, que são francamente duas cortesãs, mas que alternam com tanta

\footnotetext{
${ }^{24}$ JACOBBI. Bom dia, Mirandolina, p. 11.

${ }^{25}$ JACOBBI. Bom dia, Mirandolina, p. 11.
} 
facilidade as duas linguagens: a retórica gongorizante dos "repertórios", cenas e frases feitas, e a gíria diária do palco: "o trouxa", "o camelo", o achado irresistível de "meter os peitos na bandeja" com que as Lollobrigidas da época, colocadas na porta do teatro, atraíam as belas e grandes moedas de ouro e de prata, "com direito ao beliscão"... ${ }^{26}$

Ao compreender Mirandolina como uma síntese, mais elaborada, tanto dramaturgicamente quanto psicológica e socialmente, das Colombinas da commedia dell'arte, Ruggero Jacobbi revela uma concepção muito distante daquela de Visconti, ou mesmo de Stanislávski. Na cena de Visconti, Mirandolina é caracterizada como uma mulher representante da burguesia, fria e calculista, cuja luta contra a misoginia do Cavaleiro de Ripafratta é o sintoma de um conflito de classe radical e insolúvel. $\mathrm{O}$ seu jogo de sedução é engendrado sob a luz da vantagem e da afirmação social. ${ }^{27}$ Jacobbi, ao contrário, enxerga Mirandolina como uma figura dotada de graça, leveza e beleza, mais próxima a uma faceirice própria das mulheres do povo, ou melhor, daquelas criadas "endiabradas" dos enredos das comédias populares.

Esta diferença de perspectiva no que diz respeito à figura da protagonista da peça pode ajudar a explicar o fato de que, segundo a crítica teatral do período, Maria Della Costa não se "encontrou" no papel. Miroel Silveira - que era um dos diretores artísticos do Teatro Popular de Arte - ressaltou que o espetáculo não convencia plenamente porque havia faltado o ingrediente principal, isto é, a própria Mirandolina:

Maria Della Costa, excelente atriz em papéis de outro gênero, nada tem a ver com a alegria da 'Locandiera', toda sexo, malícia e premeditação. [...] ela faz tudo o que se espera da personagem, menos o que seria indispensável: encarná-la. ${ }^{28}$

Décio de Almeida Prado observou o mesmo descompasso:

Para Maria Della Costa, igualmente, "Mirandolina" é uma lição, que lhe será útil na medida em que ela souber compreender e aceitar. [...] Cada novo papel é um jogo,

\footnotetext{
${ }^{26}$ JACOBBI. Bom dia, Mirandolina, p. 11.

${ }^{27}$ BOSISIO. Il Teatro di Goldoni sulle Scene Italiane del Novecento.

${ }^{28}$ SILVEIRA. Mirandolina, p. 6.
} 
que se pode ganhar ou perder, sem desmerecimento. "Mirandolina" não lhe assentou perfeitamente bem, pelo menos na encenação de Ruggero Jacobbi. Não terá sido esta, certamente, a primeira vez que isto tenha acontecido a uma atriz da sua categoria, nem a última. A questão toda está em redobrar a atenção, tentando adivinhar, com a maior humildade artística, quais as personagens que convêm ao seu temperamento de mulher e de artista. ${ }^{29}$

Neste caso específico da interpretação de Maria Della Costa, é preciso levar em consideração as circunstâncias nas quais ela entrou em contato com a personagem. Vimos que ela despertou para o papel após assistir à encenação de Luchino Visconti, que apresentava uma Mirandolina essencialmente distinta daquela proposta por Ruggero Jacobbi. Talvez a linha adotada por Visconti fosse mais adequada para a "personalidade" da atriz, ou seja, Décio de Almeida Prado tinha razão ao apontar que o desempenho da atriz não tinha sido adequado na encenação e na linha proposta por Ruggero Jacobbi.

Acentuando a presença dos tipos populares ligados ao teatro de improvisação na figura das cortesãs que se disfarçam de comediantes, Jacobbi revela uma de suas concepções teatrais mais arraigadas, a saber, a necessidade de afirmação de um teatro de caráter popular capaz de promover a adesão de um público mais amplo sem, contudo, deixar de lado a possibilidade de reflexão sobre as questões humanas e sociais. A crítica teatral que apreciou o espetáculo, inclusive, deu amplo destaque à interpretação que Fernanda Montenegro fez da personagem Dejanira, que possuía características essencialmente ligadas ao teatro popular de improvisação, que fazia rir ao "meter os peitos na bandeja"30. Na própria tradução do texto, realizada por Itália Fausta e adaptada por Jacobbi, aparecem gírias próprias do linguajar popular brasileiro daqueles anos como "trouxa", "pronto", "facada", "sabidinha" que, na visão de Décio de Almeida Prado, revelavam "uma redução a uma realidade cotidiana e menor". 31

\footnotetext{
${ }^{29}$ PRADO. Mirandolina, p. 10.

${ }^{30}$ JACOBBI. Bom dia, Mirandolina, p. 11.

${ }^{31}$ PRADO. Mirandolina, p. 10.
} 
Estas formas do teatro popular também foram aproveitadas por Ruggero Jacobbi na marcação do espetáculo, conforme revela Sérgio Brito ao comentar os cenários de Gianni Ratto:

Os cenários de Gianni Ratto eram assombrosos de tão lindos. Havia uma pintura levíssima, quase etérea. Havia uma transparecia, só com árvores pintadas atrás de um telão transparente. E, todos os dias, havia palmas, quando se passava para o quarto do conde de Albafiorita... A passagem era feita com música e com uma pantomima marcada pelo Ruggero Jacobbi. Os atores puxavam as cordas que faziam descer "as cortinas" do quarto e traziam os móveis. E, o Fábio Sabag, que puxava o final, recebia salva de palmas. Me lembro que era uma pantomima maravilhosamente marcada pelo Ruggero. Ele utilizou o cenário. ${ }^{32}$

Sem perder de vista as formas do teatro popular, em Mirandolina a ênfase dada por Ruggero Jacobbi recaiu sobre os significados históricos do seu enredo:

Aqui [em Mirandolina], é que o realismo psicológico se entrosa com o realismo social. A primeira cena da peça é exemplar nesse sentido, é um retrato completo da sociedade do século XVIII. O novo rico e o aristocrata discutem pelo amor de uma hoteleira. Um deles comprou o título de conde no mesmo dia em que o outro vendeu o título de marquês. O terceiro estado (Fabrício) procura fazer-se através do casamento e solidariza-se com o novo rico, na base irresistível das gorjetas. São as várias camadas da nova classe dominante, da burguesia, que se formam, se entrelaçam, se devoram umas às outras. É um mundo que está subindo e que, dali a pouco, vai tomar de assalto a Bastilha. ${ }^{33}$

Com o olhar privilegiado do intérprete que tem ao seu lado a perspectiva temporal, Ruggero Jacobbi interpreta Mirandolina como a síntese da formação do mundo moderno, onde a burguesia irá afirmar o seu projeto político e cultural. O povo também se faz presente (Fabrício),

${ }^{32}$ GIANNELLA. Contribuição para o estudo do "Moderno Teatro Brasileiro".

${ }^{33}$ JACOBBI. Bom dia, Mirandolina, p. 12. 
mas se encontra vinculado à classe da qual depende para sobreviver por meio das novas relações de trabalho que se estabelecem. Neste ponto, Jacobbi se mostra afinado com o realismo de Visconti onde, a partir da sugestão apontada por Roland Barthes ${ }^{34}$, a vitória de Mirandolina sobre a misoginia do Cavaleiro se completa na cena em que ela passa os lençóis, ou seja, Visconti utiliza a "mediação dos objetos" - neste caso um simples ferro de passar - para lançar luz sobre a "passagem" do tempo que concretiza a vitória absoluta da burguesia sobre a nobreza. Os olhos dos dois, neste sentido, estão voltados para a Revolução Francesa, conforme o próprio Jacobbi apontou anteriormente: Mirandolina é o retrato da subida de um mundo que vai tomar de assalto a Bastilha.

Mas isto não significa que o diretor lê o texto somente como um documento histórico de uma época fundamental para a compreensão do mundo moderno. Ele avança na interpretação ao associar Mirandolina a Fígaro, de Beaumarchais, como visionários de um mundo novo, ainda marcado pela esperança:

O novo século nasce com o sorriso e as trapalhadas de duas personagens: a hoteleira Mirandolina e o barbeiro Fígaro. $\mathrm{O}$ sorriso é de revolta. As trapalhadas são a defesa instintiva de quem muito apanhou, durante séculos, e agora não pode ser bom; prefere ser experto. Mas ambos olham para o mundo novo; ambos apontam os terríveis caminhos da esperança. Pouco tempo depois, teremos os atrozes heróis de outra revolta e os mártires de outra resignação: o salteador Karl Moor e o soldado raso Woyzeck. Tempo das grandes crises do Ocidente: de uma crise que dura até hoje. ${ }^{35}$

Fica evidente, nesta passagem, que o interesse do diretor não é fornecer um retrato histórico das contradições sociais do século XVIII, mas, sobretudo, buscar explicitar as maneiras como aquelas questões postas pelo texto de Goldoni podem se relacionar com o mundo contemporâneo. Por isso, ele faz um exercício de pensar como a defesa, cômica e irônica, de novos valores civis e sociais empreendida por Mirandolina e Fígaro irá gestar um mundo novo, que se torna concreto, na visão de Jacobbi, com a Revolução Francesa. Entretanto, este mesmo mundo novo, esta esperança que se revela terrível, terá as

\footnotetext{
${ }^{34}$ BARTHES. La Locandiera, p. 54.

${ }^{35}$ JACOBBI. Bom dia, Mirandolina, p. 12.
} 
suas idiossincrasias reveladas com o aparecimento de outro elemento na discussão política e moral no século XIX, a saber, o "povo" - e as referências aos personagens de Schiller e Büchner remetem ao poder de crítica à moral e à nova hierarquia social que a burguesia reproduz -, cujas "revoltas" desencadearão uma crise, não resolvida, ainda perceptível em meados do século XX.

Estas intenções assumidas por Ruggero Jacobbi na encenação de Mirandolina serão questionadas na crítica realizada por Décio de Almeida Prado, para quem o diretor desrespeitou o texto de Goldoni, acabando por lhe emprestar "intenções que certamente ele nunca teve":

Não há dúvidas de que na peça vemos "um mundo que está subindo e que dali a pouco vai tomar de assalto a Bastilha". Mas não existe a intenção polêmica, senão revolucionária, característica de "O Casamento de Fígaro". Entre Beaumarchais e Goldoni vai toda a diferença que separa o homem de ação, voltado momentaneamente para a literatura, usando-a, em parte, como instrumento político, e o puro artista, o puro homem de teatro. Dar à "Mirandolina" mais peso, mais substância histórica, mais gravidade do que ela mesma deseja ter, é um erro que naturalmente tem o seu preço, como qualquer outro, porque a arte também costuma vingar-se dos que não acreditam em sua soberania. ${ }^{36}$

O descompasso entre a encenação de Ruggero Jacobbi e a apreciação de Décio de Almeida Prado deriva, sobremaneira, da concepção do crítico da autonomia da obra de arte de matriz essencialmente idealista. Almeida Prado não pode perdoar o fato de que o diretor buscou no espetáculo inferir significados mais complexos do que aqueles que o dramaturgo impôs ao texto. Analisando esta mesma crítica de Décio de Almeida Prado, Beti Rabetti indica que nela podem ser vistos "indicadores significativos para o estabelecimento de alguns dos parâmetros que balizam o teatro brasileiro moderno naqueles anos":

Trata-se de defender a autonomia da arte teatral e de colocar a seu serviço, apenas (e isso é muito para aqueles anos) aquilo que ela requer, ou exige, sob a pena de se pagar

${ }^{36}$ PRADO. Mirandolina, p. 10. 
um alto preço pela sua "vingança". Se, dali a alguns anos, não bastará mais ser "artista", neste momento, é preciso, sobretudo, salvaguardar o "estatuto artístico do teatro", conseguido a duras penas até então, garantido sobretudo pelo respeito às exigências de um texto altamente qualificado. ${ }^{37}$

O crítico finaliza a sua apreciação apontando que, em sua visão, Ruggero Jacobbi, enquanto crítico e encenador, adotava, frequentemente, dois critérios distintos de julgamento: o estético e o político. Para ele, não se poderia observar um objeto de dois ângulos ao mesmo tempo e que o diretor deveria decidir, para se elevar nos dois sentidos, se desejava "servir ao teatro ou à sua concepção de arte interessada". ${ }^{38} \mathrm{O}$ crítico não percebia, com efeito, que o diretor pensava a encenação dos seus espetáculos a partir de outra concepção, orgânica, em que os dois critérios não podiam existir isoladamente um sem o outro.

\section{Considerações finais}

A análise de três encenações de textos de Carlo Goldoni realizadas por Ruggero Jacobbi entre 1949 e 1955 revela que o diretor italiano radicado no Brasil teve um papel central na mudança de ênfase e no aprofundamento teórico e estético sobre a obra do dramaturgo. A sequência em que os textos foram encenados - Arlequim, servidor de dois amos; O Mentiroso; e Mirandolina - é sintomática da existência de um projeto em mostrar ao espectador brasileiro a poética em movimento da reforma teatral realizada por Goldoni. Em outras palavras, Jacobbi não somente explica em palavras a reforma da comédia feita por Goldoni no século XVIII, como demonstra cenicamente estas transformações a partir da interpretação de três textos característicos do projeto artístico e cívico do comediógrafo.

Isso não significa, entretanto, que Ruggero Jacobbi tenha realizado uma intepretação arqueológica da dramaturgia para mostrar aos espectadores brasileiros que "Goldoni era assim". Esperamos ter demonstrado que Jacobbi buscou o tempo todo o diálogo com o seu público contemporâneo, isto é, procurou aproximar estética e politicamente os textos e formas do teatro goldoniano da realidade artística e social brasileira

${ }^{37}$ GIANNELLA. Contribuição para o estudo do "Moderno Teatro Brasileiro", p. 298. ${ }^{38}$ PRADO. Mirandolina, p. 10. 
do período. Nestes exercícios, o diretor demonstrou uma especial atenção às formas do teatro popular como oposição a determinada estética teatral que predominava em determinados circuitos teatrais do chamado teatro brasileiro moderno. A interpretação de Carlo Goldoni por Ruggero Jacobbi, neste sentido, é reveladora não apenas de uma nova maneira de "ler" o dramaturgo, mas abre novas possibilidades para questionar a própria historiografia do teatro brasileiro moderno.

\section{Referências}

BARTHES, Roland. La Locandiera. In: BARTHES, Roland. Escritos sobre teatro. Textos reunidos e apresentados por Jean-Loup Rivière. Tradução de Mário Laranjeira. São Paulo: Martins Fontes, 2007.

BOSISIO, Paolo. Il Teatro di Goldoni sulle Scene Italiane del Novecento. Milano: Electa, 1992.

DORT, Bernard. Por que Goldoni, hoje? In: DORT, Bernard O Teatro e a sua Realidade. Tradução de Fernando Peixoto. São Paulo: Perspectiva, 1977.

DUARTE, André Luis Bertelli. Apropriações históricas e releituras estéticas da comédia de Carlo Goldoni pela modernização artística no Brasil do século XX. 2015. Tese (Doutorado em História). Universidade Federal de Uberlândia, Uberlândia, 2015.

DUARTE, André Luis Bertelli. O caráter na comédia de Carlo Goldoni: apropriações históricas de "O mentiroso" (Il Bugiardo) entre a Itália e o Brasil. In: PATRIOTA, Rosangela; RAMOS, Alcides Freire. Circularidades políticas e culturais: formas - circuitos - recepção. São Paulo: Verona, 2017. p. 52-76.

FIDO, Franco. Guida a Goldoni: teatro e società nel Settecento. Torino: Einaudi, 1977.

FURQUIM, Luís. Onde o Arlequim se confunde com o malandro brasileiro. Jornal de Notícias, Rio de Janeiro, p. 3, 12 mar. 1949.

GIANNELLA, Maria de Lourdes. Contribuição para o estudo do "Moderno Teatro Brasileiro": a contribuição italiana. 1989. Tese (Doutorado em História). Universidade de São Paulo, São Paulo, 1989. 
GOLDONI, Carlo. O Mentiroso. Tradução de Ruggero Jacobbi para o espetáculo do Teatro Brasileiro de Comédia. Departamento Estadual de Imprensa e Propaganda (DEIP/SP), ]1949?]. Datilografado.

GOLDONI, Carlo. O teatro cômico. Tradução de Olga Navarro. Texto do acervo de Sandro Polônio pertencente ao acervo de peças teatrais da biblioteca da Universidade Federal de Uberlândia, [1958?], p. 27-28. Datilografado.

JACOBBI, Ruggero. Bom dia, Mirandolina. Programa do espetáculo "Mirandolina”. São Paulo, Teatro Maria Della Costa, 1955.

JACOBBI, Ruggero. Goldoni e a "commedia dell'arte". In: VANUCCI, Alessandra (org). Crítica da razão teatral: o teatro no Brasil visto por Ruggero Jacobbi. São Paulo: Perspectiva, 2005. p. 73-87.

JACOBBI, Ruggero. Meditazioni su um mito e su una biografia. Le rondini di Spoleto. Firenze, 1962.

JACOBBI, Ruggero. Reflexões sobre "O mentiroso”. In: PROGRAMA do espetáculo “O Mentiroso". São Paulo: Teatro Brasileiro de Comédia, 1949.

MAGNO, Paschoal Carlos. Estréia, hoje, no Ginástico, "Arlequim, servidor de dois amos", de Goldoni, pelo "Teatro dos Doze". Correio da Manhã, Rio de Janeiro, p. 13, 09 set. 1949.

PRADO, Décio de Almeida. "Mirandolina". O Estado de São Paulo, São Paulo, p. 10, 17 jul. 1955.

RAULINO, Berenice. Ruggero Jacobbi: presença italiana no teatro brasileiro. São Paulo: Perspectiva: FAPESP, 2002.

SILVEIRA, Miroel. "Mirandolina”. Folha da Manhã, Rio de Janeiro, p. 6, 30 ago. 1955 .

Recebido em: 5 de junho de 2018. Aprovado em: 22 de fevereiro de 2019. 